\title{
ORGANOSILICON PLASMA POLYMERS DEPOSITED IN TRIMETHYLSILYL ACETATE/CH PLASMA OF CAPACITIVELY COUPLED RF GLOW DISCHARGE
}

\author{
1'Štěpánka KELAROVÁ, ' ${ }^{1}$ Monika STUPAVSKÁ, ${ }^{1}$ Roman PŘIBYL, 'Vilma BURŠíKOVÁ \\ ${ }^{1}$ Masaryk University, Faculty of Science, Brno, Czech Republic, EU, kelarova.s@mail.muni.cz
}

https://doi.org/10.37904/nanocon.2020.3773

\begin{abstract}
Thin solid films based on organosilicon monomers are perspective in many branches of industry as well as for bioapplications. In the present study, plasma of RF capacitively coupled glow discharge in gaseous mixture of trimethylsilyl acetate (TMSA) monomer and methane was used to create $\mathrm{SiO}_{x} \mathrm{C}_{y} \mathrm{H}_{z}$ coatings. This study monitors properties of resulting thin films (surface chemistry, wettability, surface structure and mechanical properties) in dependency on deposition parameters. The main subject of the presented research is the investigation of the relationship between the above-mentioned properties of prepared organosilicon coatings and the flow rate ratio of TMSA monomer and $\mathrm{CH}_{4}$ carrier gas applied during deposition process.
\end{abstract}

Keywords: Trimethylsilyl acetate, PECVD, XPS, microindentation, confocal microscopy

\section{INTRODUCTION}

Thin solid films based on organosilicon monomers have a wide application range in many industrial fields. Organosilicon materials prepared using plasma techniques can be successfully used as anti-scratch layers on plastic substrates, corrosion protection coatings, barrier films, super-hydrophobic coatings, anti-reflection coatings for solar cells etc. [1]. The PECVD process leads to wide variation of organosilicon-based coatings from inorganic $\mathrm{SiO}_{2}$-like materials [1-4], through soft organic $\mathrm{SiO}_{x} \mathrm{C}_{y} \mathrm{H}_{2}$ plasma polymers [1-4] to DLC films doped by silicon and oxygen atoms [5-7]. Desired properties of organosilicon material are achieved by optimization of deposition process, including the choice of proper precursor, carrier gas $\left(\mathrm{Ar}, \mathrm{O}_{2}, \mathrm{CH}_{4}\right.$ etc.) and other factors of used discharge like gas pressure, supplied power, bias voltage etc. [1-8]. Tetraethoxysilane (TEOS) [2], hexamethyldisiloxane (HMDSO) [3-7] and trimethylsilane (TMS) [8] and are among the most widely used monomers for preparation of organosilicon coatings.

The present work is focused on preparation and characterization of $\mathrm{SiO}_{x} \mathrm{C}_{y} \mathrm{H}_{z}$ films prepared from gaseous mixture of trimethylsilyl acetate (TMSA) monomer and methane using plasma of RF capacitively coupled discharge. Unlike commonly used precursors mentioned above, TMSA monomer described by linear formula $\mathrm{CH}_{3} \mathrm{CO}_{2} \mathrm{Si}\left(\mathrm{CH}_{3}\right)_{3}$ includes $\mathrm{C}=\mathrm{O}$ group in its structure [1], which makes it very perspective not only for industrial applications, but also for preparation of carbonyl-functionalized organosilicon coatings suitable for bioapplications. The main aim of this study is to find the relationship between properties (chemical composition, mechanical properties, surface structure and degree of hydrophobicity) of prepared TMSA-based materials and the flow rate ratio $R$ of methane in the used gaseous mixture.

\section{EXPERIMENTAL}

Organosilicon thin films were prepared in capacitively coupled RF glow discharges at low pressures of $\sim 40 \mathrm{~Pa}$ from mixture of TMSA and methane in the parallel plate reactor. The bottom electrode served as the silicon substrate holder. This electrode was coupled to RF generator (13.56 MHz) via a blocking capacitor. The supplied power was kept constant at $75 \mathrm{~W}$ for all depositions. The flow rates of used monomer and $\mathrm{CH}_{4}$ carrier gas were varied. Changes of the flow rates are represented by the ratio $R$ of methane in gaseous mixture 
given by an equation (1), where $Q_{\mathrm{CG}}$ means the flow rate of $\mathrm{CH}_{4}$ carrier gas and $Q_{\mathrm{M}}$ means the flow rate of TMSA monomer in sccm. Flow rates of used gases varied in range from $0.5 \mathrm{sccm}$ to $6.5 \mathrm{sccm}$. A total flow rate of gaseous mixture was kept at $7 \mathrm{sccm}$ for all depositions. The bias voltage varied from $-60 \mathrm{~V}$ to $-300 \mathrm{~V}$.

$$
R=\frac{Q_{\mathrm{CG}}}{Q_{\mathrm{CG}}+Q_{\mathrm{M}}}
$$

Properties of the prepared films were studied by several characterization methods. Chemical composition of TMSA-based surfaces was determined by X-ray photoelectron spectroscopy (XPS). XPS spectra of studied films were measured using Escalab 250Xi device (ThermoFisher Scientific) using an X-ray source AlKa. All spectra were measured with the energy step of $0.01 \mathrm{eV}$ with a pass energy of $20 \mathrm{eV}$. Atomic concentrations of individual elements (silicon, carbon, oxygen) presented on the studied surfaces were calculated from measured data using the Avantage software. Concentrations of different chemical bonds were determined by fitting Si $2 p$ and $C 1$ s signals.

The degree of surface hydrophobicity of each coating was determined by water contact angle measurements using Krüss DSA 30 device. Surface topography was observed by confocal laser microscope LEXT OLS4000 using high magnification (400x-800x).

Mechanical properties (Indentation hardness $H_{\mathrm{IT}}$ and effective elastic modulus $E$ ) were measured using Hysitron TI 950 (Bruker) nanoindentation device. The standard Berkovich diamond indenter with tip radius of approx. $70 \mathrm{~nm}$ was used for nanoindentation tests. Quasistatic nanoindentation tests with 20 partial unloading segments were used to study the depth profile of the hardness $H_{I T}$ and the effective elastic modulus $E$. Each indentation test was repeated at least 10 times. The maximum indentation load was in the range from 0.1 to $11 \mathrm{mN}$. The mechanical parameters were determined at indentation depths less than $1 / 10$ of film thickness to avoid any substrate effect.

\section{RESULTS AND DISCUSSION}

\subsection{Surface chemistry}

The surface chemistry of prepared TMSA-based coatings was determined using XPS analysis. Figure 1a shows an evolution of concentration of carbon atoms presented at studied surfaces in dependency on the methane ratio $R$ defined by the equation 1 . The carbon concentration varied between 45 at. $\%$ and 48 at. $\%$ if the ratio $R$ in range of $0.07-0.50$ was used during PECVD process. TMSA-based coatings prepared using high ratios of methane in gaseous mixture showed significantly higher incorporation of carbon atoms into the resulting surface structure. Increasing ratio $R$ from 0.50 to 0.86 led to the increase in carbon concentration from 45 at. \% to 68 at. \% (Figure 1a). Further increase of the methane content in gaseous mixture to the $R=0.93$ caused decrease of concentration of carbon atoms at the resulting organosilicon thin film to 59 at. \%.

Concentrations of carbon bonds presented at prepared surfaces were determined by fitting of $C$ is signals. TMSA-based coatings included significant content of $\underline{\mathrm{C}}-\mathrm{C} / \underline{\mathrm{C}} \mathrm{H}_{\mathrm{x}}$ bonds (binding energy $\mathrm{BE}=284.8 \mathrm{eV}$ ) and $\underline{\mathrm{C}}-\mathrm{Si}$ bonds $(B E=284.2 \mathrm{eV})$. Carbon bonded to oxygen atoms was presented mainly in $\underline{\mathrm{C}}-\mathrm{O}$ links $(\mathrm{BE}=286.1 \mathrm{eV})$. Carbonyl groups $(\mathrm{BE}=287.6 \mathrm{eV})$ and carboxyl groups $(\mathrm{BE}=289.4 \mathrm{eV})$ were detected at studied surfaces as well, however concentrations of these bonds varied from $1.6 \%$ to $3 \%$ of carbon atoms at all prepared surfaces. The only one exception was the thin film prepared using ratio $R=0.5$ where concentration of $\underline{C}=0$ bonds reached up to the $5 \%$ of carbon atoms. Figure 1 shows trends of concentrations of previously mentioned significant carbon bonds: $\underline{\mathrm{C}}-\mathrm{C} / \underline{\mathrm{C}} \mathrm{H} \times \underline{\mathrm{C}}-\mathrm{Si}$ and $\underline{\mathrm{C}}-\mathrm{O}$.

Based on the experimental results, concentration of $\underline{\mathrm{C}}-\mathrm{C} / \underline{\mathrm{C}} \mathrm{H}_{\mathrm{x}}$ bonds at studied TMSA-based surfaces varies between $73-87 \%$ of carbon atoms (Figure 1b). The minimum concentration of $\underline{\mathrm{C}}-\mathrm{C} / \underline{\mathrm{C}} \mathrm{H}_{\mathrm{x}}$ chains was determined at TMSA-based coating prepared using the methane ratio of $R=0.50$ (Figure 1b). 

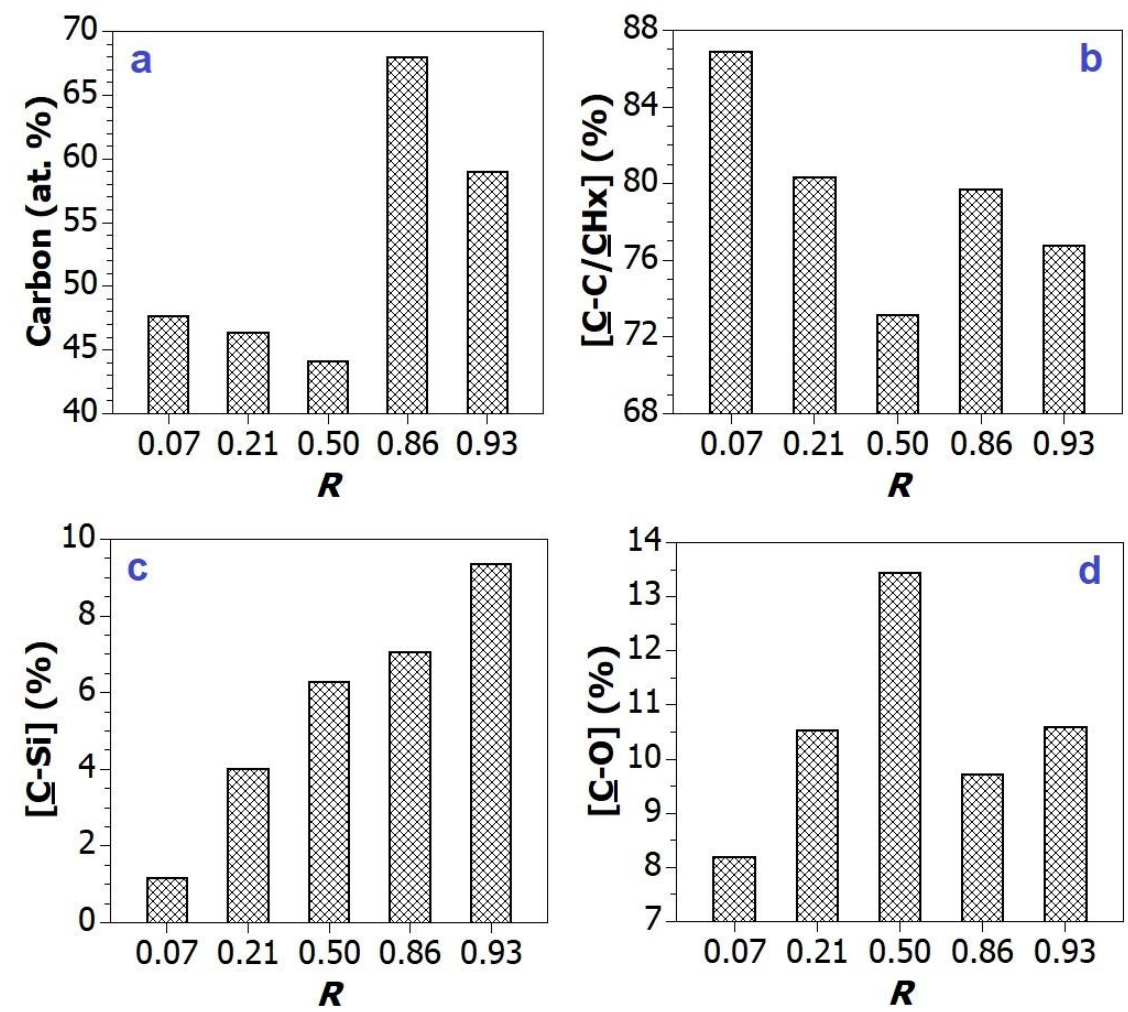

Figure 1 An atomic concentration of the surface carbon atoms and percentage content of the significant carbon bonds in dependency on the ratio $R$.

The evolution of $\underline{\mathrm{C}}-\mathrm{Si}$ concentration shown in Figure $1 \mathrm{c}$ is gradually increasing from $1 \%$ to $9 \%$ of carbon with an increasing methane ratio $R$ in range of $0.07-0.93$, although the number of silicon atoms presented at studied TMSA coatings is rather decreasing (see Figure $\mathbf{2 b}$ ).

The percentage concentration of $\underline{\mathrm{C}}-\mathrm{O}$ bonds presented at the prepared TMSA coatings shows nonlinear trend (Figure 1d) complementary to the evolution of $\underline{\mathrm{C}}-\mathrm{C} / \underline{\mathrm{C}} \mathrm{H}_{\mathrm{x}}$ bonds (Figure 1b). The lowest concentration of these links was detected at TMSA-based surface prepared using $R=0.07$ and the highest concentration of $\underline{\mathrm{C}}-\mathrm{O}$ groups was observed at thin film prepared using the ratio $R=0.50$.

For TMSA coating including the highest ratio of $\underline{\mathrm{C}}-\mathrm{O}$ links is also characteristic the most significant integration of oxygen atoms into the surface structure (see Figure 2a). This coating prepared using $R=0.50$ shows 32 at. \% of oxygen at the surface. The increase of the methane ratio $R$ from 0.50 to 0.86 led to significant drop in the oxygen concentration: the resulting coating included only 21 atomic $\%$ of oxygen in its structure. The atomic concentration at the rest of prepared TMSA coatings was $\sim 27$ at. $\%$.

The atomic concentration of silicon can be considered stable at 26 at. \% in range of applied $\mathrm{CH}_{4}$ ratios $R$ in range from 0.07 to 0.50 (see Figure $\mathbf{2 b}$ ). The next increase of the ratio $R$ caused rapid decrease in silicon concentration. The content of silicon atoms at TMSA coatings prepared using ratios 0.86 and 0.93 varies between 11 at. \% and 14 at. \%.

Silicon atoms present at the surface of prepared TMSA coatings were bonded in the highly oxidized $\underline{\mathrm{SiO}}_{4}$ links $(\mathrm{BE}=103.7 \mathrm{eV})$ or in $\mathrm{X} \underline{\mathrm{SiO}}_{\mathrm{m}}$ bonds where $\mathrm{X}$ represents carbon or hydrogen atom. The concentration of $\underline{\mathrm{SiO}}_{4}$, which varies from $17 \%$ to $24 \%$ of silicon atoms (Figure 2c), is low compared to the $\mathrm{XSiO}_{3}$ structures that shows values of concentrations between $40-53 \%$ (Figure 2d). Increased values of $\mathrm{XSiO}_{3}$ are probably a result of integration of carbon atoms from the carrier gas into resulting TMSA-based coatings. However, based on 
the XPS analysis we are not able to discuss the influence of hydrogen integration on the trend of $\mathrm{X}_{\mathrm{n}} \underline{\mathrm{SiO}}_{\mathrm{m}}$ structures (Figure 2d-f).

Another significant silicon structures are $\mathrm{X}_{2} \underline{\mathrm{SiO}}_{2}$ links that show a decreasing trend from $37 \%$ to $20 \%$ with the increasing ratio $R$ from 0.07 to 0.93 (Figure 2e). Concentration of $\mathrm{X}_{2} \underline{\mathrm{SiO}}_{2}$ bonds can be considered stable at $25 \%$ of $\mathrm{Si}$ in range of methane ratios from 0.21 to 0.86 .

Concentration of $\mathrm{X}_{3} \underline{\mathrm{SiO}}$ structures are very low in comparison with other silicon components (see Figure 2f). The most of studied coatings shows concentrations of these bonds in range of 1-4 \%. The only one exception is TMSA-based surface prepared using ratio $R=0.86$ where concentration of $X_{3}$ SiO structures reaches the value of $14 \%$.
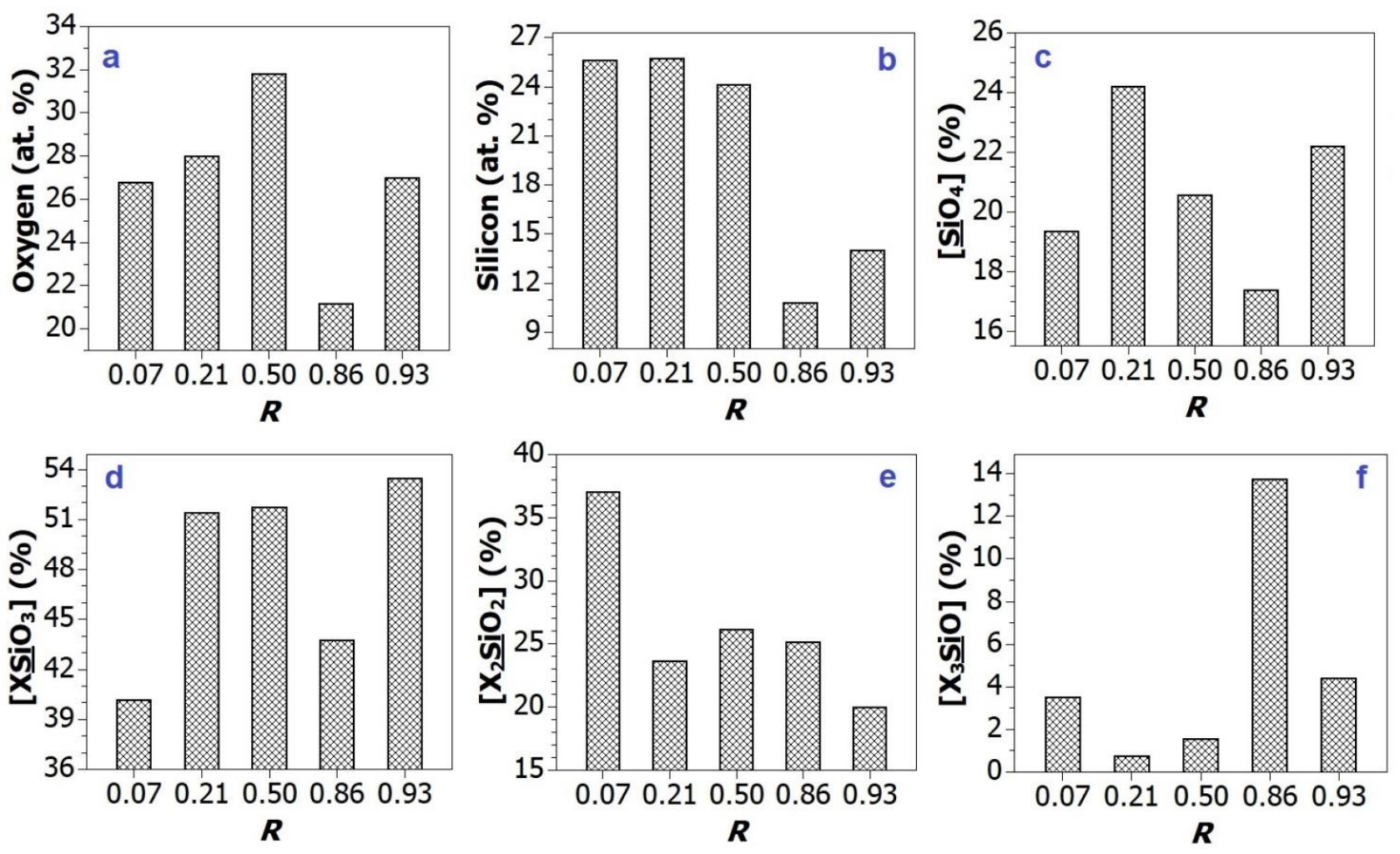

Figure 2 An atomic concentration of the surface oxygen and silicon in dependency on the ratio $R$. Figure includes evolution of percentage content of the identified silicon bonds as well.

\subsection{Mechanical properties}

Indentation hardness $H_{\mathrm{T}}$ and effective elastic modulus $E$ were determined using microindentation technique (Section 2) for all studied TMSA-based coatings. Values of these parameters were relatively low in case of thin films prepared using ratios $\mathrm{R} \leq 0.50$ (Figure 3). Values of indentation hardness varied from $0.7 \mathrm{GPa}$ to $2.3 \mathrm{GPa}$ in this range of $R$ and effective elastic modulus was below $20 \mathrm{GPa}$. TMSA-based coatings prepared using $R$ in range from 0.07 to 0.50 can be considered as a soft polymeric materials [1]. An increase of methane ratio $R$ to 0.86 and 0.93 led to the rapid increase of $H_{1 T}$ and $E$ (Figure 3). Thin films prepared using high ratios of $\mathrm{CH}_{4}$ were characteristic by indentation hardness equal to $11 \mathrm{GPa}$ and by elastic modulus $\sim 95 \mathrm{GPa}$. These TMSA-based materials showed mechanical properties of highly cross-linked DLC coatings [6,7]. 

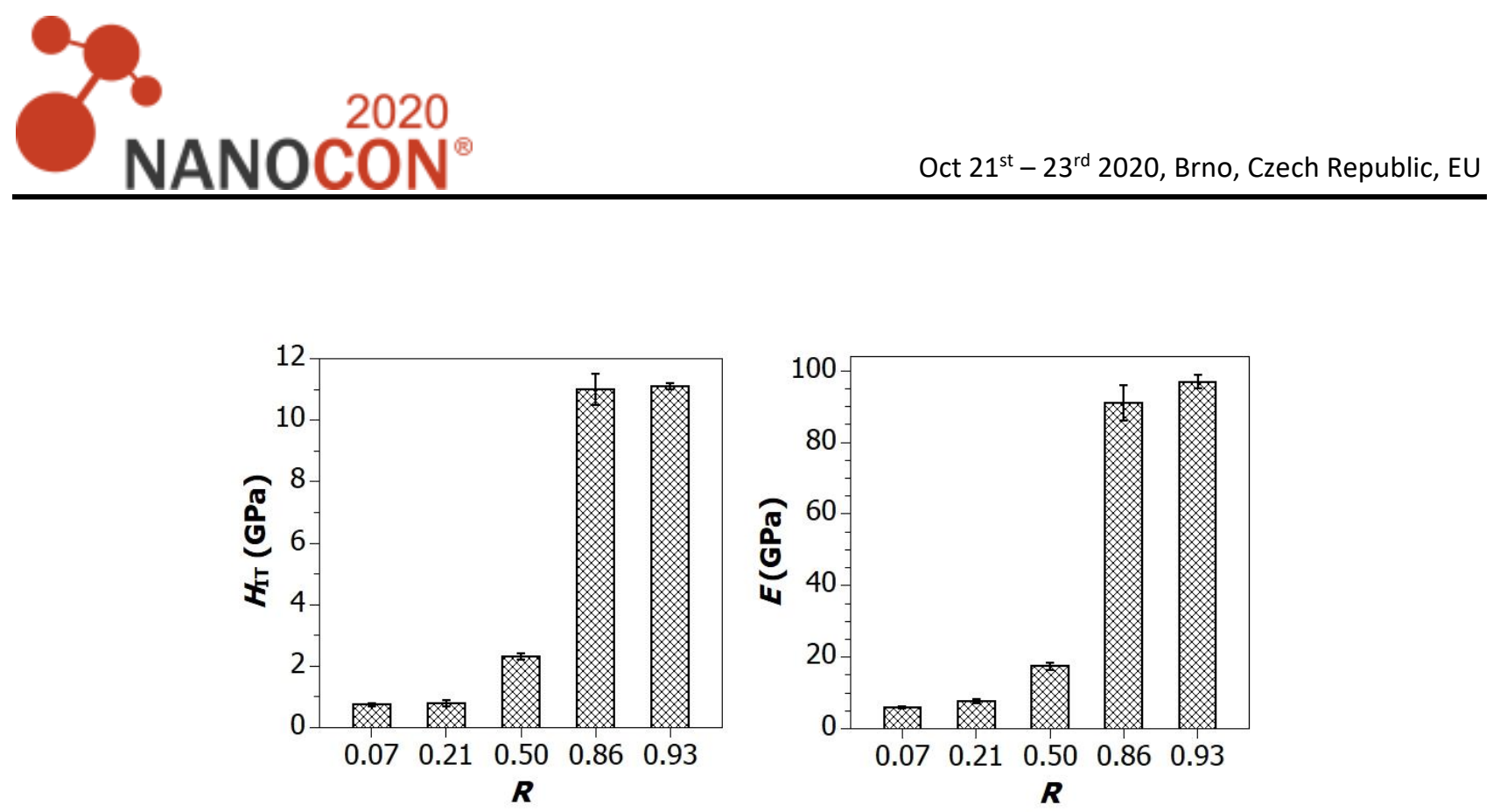

Figure 3 An evolution of the indentation hardness $H_{\text {TT }}$ (left) and effective elastic modulus $E$ (right) in dependency on the methane ratio $R$

\subsection{Surface structure and wettability}

Figure 4 shows an example of surface structures of three chosen TMSA-based coatings which were determined using confocal microscopy (Section 2). Based on the results, structure of deposited thin films gradually changes from the surface covered with protrusions to the surfaces including defects in the form of holes (Figure 4). Observed changes may be related with the degree of crosslinking of prepared materials.
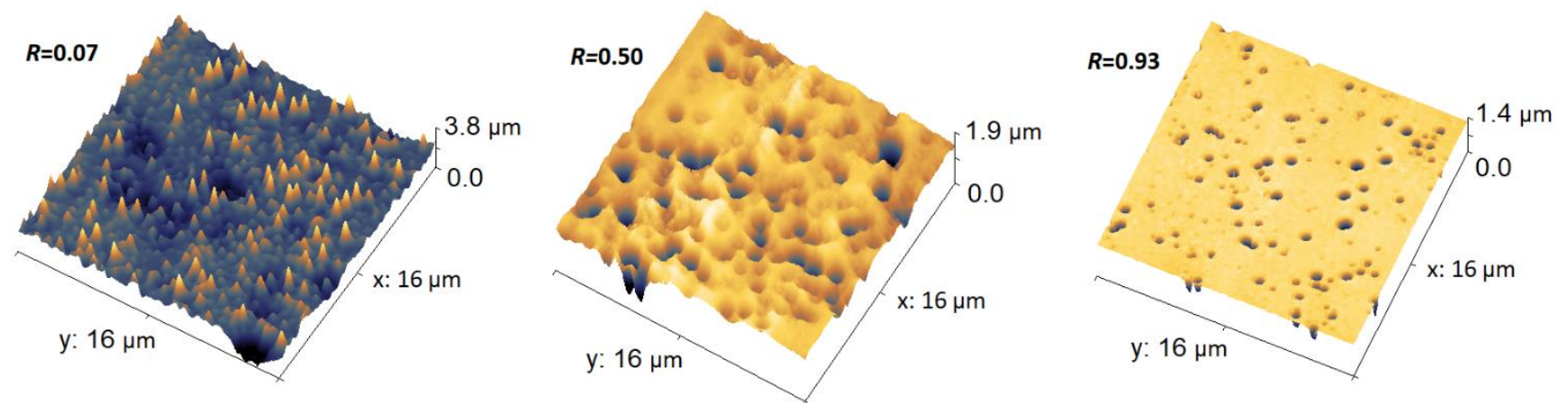

Figure 4 Examples of surface structures of three chosen coatings prepared using different ratios $R$

Degree of surface hydrophobicity was determined by water contact angle measurements. Values of water contact angle gradually decreased from $93^{\circ}$ to $81^{\circ}$ with an increasing ratio $R$ from 0.07 to 0.93 . Decrease of hydrophobicity of prepared coatings is connected with concentrations of different chemical structures presented at studied surfaces (Figure 1, 2). The most hydrophilic TMSA-based coatings with water contact angle equal to $81^{\circ}$ were prepared using high ratios $R$ equal to 0.86 and 0.93 . Since these coatings showed at the same time high values of indentation hardness (Section 3.2), the degree of hydrophobicity is probably connected with a degree of crosslinking as well.

\section{CONCLUSION}

In the present work, organosilicon coatings were prepared using $\mathrm{TMSA} / \mathrm{CH}_{4}$ plasma of capacitively coupled RF glow discharge using different ratios of methane $R$ in the gaseous mixture. The variation of the ratio $R$ had a significant impact on the chemical composition of resulting surfaces as well as on the surface structure and wettability. The increase of the methane ratio $R$ caused increased integration of carbon atoms into the resulting organosilicon structures at the expense of oxygen and silicon atoms presented in TMSA monomer. TMSA- 
based coatings had rather hydrophobic character: determined values of water contact angle varied between $81-93^{\circ}$.

This study proves that it is possible to prepare hydrophobic soft polymeric materials as well as hard DLC coating doped by silicon and oxygen atoms using different ratios of methane. The hard coatings characteristic by indentation hardness equal to $11 \mathrm{GPa}$ and effective elastic modulus of $\sim 95 \mathrm{GPa}$ were achieved by using high ratios of methane in gaseous mixture $R \geq 0.86$.

\section{ACKNOWLEDGEMENTS}

The present work was supported by Czech Science Foundation under project GACR 19-15240S and by the project LM2018097 funded by Ministry of Education Youth and Sports of the Czech Republic. Štěpánka Kelarová is Brno Ph.D. Talent Scholarship Holder-Funded by the Brno City Municipality.

\section{REFERENCES}

[1] KELAROVÁ, Š., HOMOLA, V., STUPAVSKÁ, M., ČERMÁK, M., VOHÁNKA, J., PŘIBYL, R., ZÁBRANSKÝ, L., BURŠíKOVÁ, Deposition of organosilicon coatings from trimethylsilyl acetate oand oxygen gases in capacitively coupled RF glow discharge. Progress in Organic Coatings. 2020, vol. 149, pp. 105927.

[2] GOULLET, A., VALLÉE, C., GRANIER, A. and TURBAN, G. Optical spectroscopic analyses of OH incorporation into $\mathrm{SiO}_{2}$ films deposited from $\mathrm{O}_{2}$ tetraethoxysilane plasmas. Journal of Vacuum Science \& Technology A: Vacuum Surfaces and Films. 2000, vol. 18, no. 5.

[3] BOUSQUET, A., BURSIKOVA, V., GOULLET, A., DJOUADI, A., ZAJICKOVA, L., GRANIER, A. Comparison of structure and mechanical properties of $\mathrm{SiO}_{2}$-ike films deposited in $\mathrm{O}_{2} / \mathrm{HMDSO}$ pulsed and continuous plasmas. Surface and Coatings Technology. 2006, vol. 200, no. 22-23, pp. 6517-6521.

[4] BORVON, G., GOULLET, A., MELLHAOUI, X., CHARROUF, N., GRANIER, A. Electrical properties of lowdielectric-constant films prepared by PECVD in $\mathrm{O}_{2} / \mathrm{CH}_{4} / \mathrm{HMDSO}$. Materials Science in Semiconductor Processing. 2003, vol 5, no. 2-3, pp. 279-284.

[5] BURŠíKOVÁ, V., SLÁDEK, P., SŤAHEL, P., ZAJÍČKOVÁ, L. Improvement of the efficiency of the silicon solar cells by silicon incorporated diamond-like carbon antireflective coatings. Journal of Non-Crystalline Solids. 2002, vol. 299-302, no. 12, pp. 1147-1151.

[6] CHEN, L.-Y., CHAU-NAN HONG, F. Effects of $\mathrm{SiO}_{x}$-incorporation hydrocarbons on the tribological properties of DLC films. Diamond and Related Materials. 2001, vol. 10, pp. 1058-1062.

[7] BATORY, D., JEDRZEJCZAK, A., SZYMANSKI, W., NIEDZIELSKI, P., FIJALKOWSKI, M., LOUDA, P., KOTELA, I., HROMADKA, M., MUSIL, J. Mechanical characterization of a-C:H:SiOx coatings synthesized using radiofrequency plasma-assisted chemical vapor deposition method. Thin Solid Films. 2015, vol. 590, pp. 299-305.

[8] COCLITE, A. M., MILELLA, A., PALUMBO, F., PEN, C.L., d' Agnostino, R. Plasma deposited organosilicon multistacks for high-performance low-carbon steel protection. Plasma Processes and Polymers. 2010, vol. 7 , no. 9-10, pp. 788-796. 